\title{
Cross-sectional Study of Cardiovascular Risk Factors among Male and Female Medical Students in Qassim University - College of Medicine Saudi Arabia
}

Sultan Al-Nohair*, Nahla Babiker, Dalal Al-Ahmari, Dalal Al-Mutairi, Khozama Al-Matroudi, Zakiyah Al-Mutairi, Rawan Al-Ahmdi, Layan Al-Mufadhi, Alhanouf Al-Wahiby, Turki Alharbi

College of Medicine, Qassim University, Buraydah, Saudi Arabia

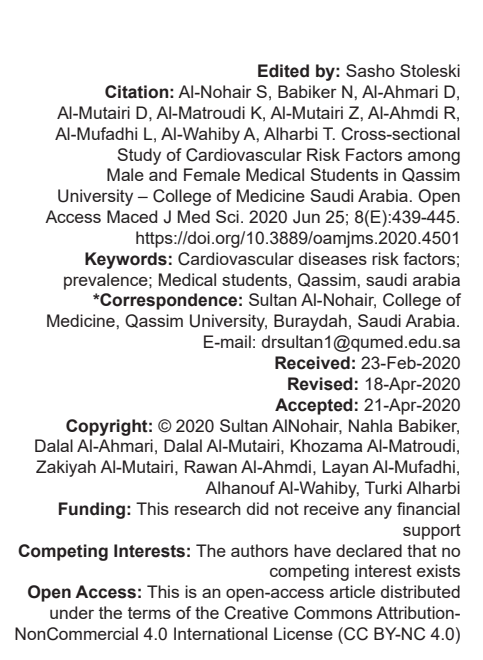

\section{Abstract}

BACKGROUND: Cardiovascular diseases (CVDs) are a major cause of mortality around the world. At present almost half of the non-communicable diseases are CVDs. According to the literature review, CVD disease and the associated risk factors are high among Saudi adults. It has not been studied to determine at which age the majority of adults acquire the risk factors. We hypothesized and planned to assess CVD risk factors among medical students. AIM: The main objective of this study is to determine the prevalence of CVD risk factors among male and female medical students in Qassim University.

METHODS: A cross-sectional study surveyed 188 males and female medical students in Qassim University. They were selected by random sampling technique. The data were collected by using a questionnaire included (age, gender, height, weight, waist circumference, blood pressure, random blood glucose, smoking habits, physical activity, and stress scale). After the data collection, it was entered and analyzed by SPSS

RESULTS: About $9.6 \%$ of male students were smokers, while there is no history of smoking among female students. About $18.2 \%$ of males were found obese, while obesity was lower among females $(4.2 \%)$. The random blood glucose for males and females was within normal limits, but the measured blood pressure showed a higher percentage of elevated blood pressure among males $(47.8 \%)$ in comparison to females $(25.4 \%)$. Perceived stress scale exhibited that females were getting a greater percentage of high stress (34.3\%), while in males, it was $14.4 \%$.

CONCLUSION: Many risk factors were greater among males, including elevated blood pressure $47.8 \%$, obesity $18.2 \%$, and smoking $9.6 \%$. On the other hand, these risk factors were lower in females, but they have a higher stress scale $34.3 \%$ in comparison to males.

\section{Introduction}

Cardiovascular diseases (CVDs) are a major cause of mortality around the world. At present, almost half of non-communicable diseases are CVDs [1]. CVDs kill 17.9 million people each year, $31 \%$ of all deaths worldwide [2]. In the middle east, the prevalence of CVD risk factors such as diabetes, hypertension, obesity, and smoking was high which determined by a study conducted; the study found that smoking was higher in men than in women, while obesity and hypertension in women were higher [3]. The smoking factor accounts for $29.7 \%$ in both populations, but Saudi students had a higher prevalence of obesity and a family history of premature coronary heart disease (CHD), while male Egyptian students have a higher prevalence of hypertension compared with male Saudi students [4]. The women of reproductive age, common endocrine disorders in (e.g. polycystic ovarian syndrome and early menopause), are linked with the accelerated development of CVD [5]. Many behavioral and nonbehavioral factors are considered as risk factors for CVDs. The behavioral factors include smoking, physical inactivity, and the use of alcohol, whereas the non-behavioral factors include hypertension, diabetes, and obesity [2]. A study compared the prevalence of risk factors for CVDs among medical students of both genders in Egypt and Saudi Arabia. The prevalence was relatively high in both. The smoking factor accounts for $29.7 \%$ in both populations, but Saudi students had a higher prevalence of obesity and a family history of premature CHD, while male Egyptian students have a higher prevalence of hypertension compared with male Saudi students [4].

A cross-sectional study was done in Saudi Arabia to determine the prevalence of diabetes among patients attending primary care clinics. The study involved 6024 subjects, 1792 (30\%) of them were diabetics; the prevalence was highest among males [6].

Regardless of race, ethnicity, or country of origin, hypertension prevalence is highest in men [7]. Framingham risk score is a multivariable statistical model that uses age, sex, smoking history, blood pressure, cholesterol, high-density lipoprotein cholesterol, and 
blood glucose levels or history of diabetes to estimate coronary event risk among individuals without previously diagnosed CHD [8].

\section{Research Methods}

This study is descriptive. A cross-sectional study, a comparative study, was conducted during the year 2019/2030 among males and females medical students which determined the prevalence of CVDs risk factors, the most common risk factor/s and identified the differences of CVD risk profile based on gender. At Qassim University, Al-Mulida, Qassim region, Saudi Arabia. Sampling, we selected our participants randomly from $1^{\text {st }}, 2^{\text {nd }}, 3^{\text {rd }}, 4^{\text {th }}$, and $5^{\text {th }}$-year male and females medical students.

The sample size calculation was conducted on www.openepi.com. Since our main hypothesis was related to CVD risk, and obesity was the most common risk factor in our target population. The sample size has been based on the prevalence estimate of obesity. The most recent estimates on obesity were $68 \%$ among women and $45 \%$ among men. Applying these estimates along with a 95\% confidence interval, $80 \%$ power, and a 2-group comparison, it was estimated that we need a minimum of 162 participants to test for differences between male and female students.

To compensate for a poor response rate and missing data, we proposed collecting a sample of 200 students. There were 719 medical students; we divided them according to the proportion into 125 males and 75 females. According to the size of the male sample, we divided them by proportion from the $1^{\text {st }}$ year to the $5^{\text {th }}$ year, $1^{\text {st }}: 21 \%(26), 2^{\text {nd }}: 19 \%(24), 3^{\text {rd }}: 19 \%(24), 4^{\text {th }}$ : $23 \%(29)$, and $5^{\text {th }}: 18 \%(22)$. Then, according to the size of the female sample, we divided them by proportion from the $1^{\text {st }}$ year to the $5^{\text {th }}$ year, $1^{\text {st }}: 22 \%(17), 2^{\text {nd }}: 21 \%$ $(16), 3^{\text {rd }}: 22 \%(17), 4^{\text {th }}: 15 \%(11)$, and $5^{\text {th }}: 19 \%(14)$. Then, we selected our sample in a simple random sampling technique by www.randomizer.org.

The collection of data was made through a questionnaire (Appendix 1) [9], [10]. The questionnaire included age, gender, height, weight, waist circumference, blood pressure, smoking habit, and stress scale. After the questionnaire, we measured the objective variables: Blood pressure, random blood glucose, body mass index, and waist circumference. Then, we collected the data to determine the risk factors of CVD among medical students. Ethical approval was taken from the Deanship of Scientific Research in Qassim University.

The variables in our study were: Age, gender, body mass index, blood glucose, blood pressure, stress, smoking habits, physical activity, and waist circumference.
The results were evaluated using the Statistical Package for the Social Sciences software. The data will be kept confidential and only the research team will be given access to the data (Appendix 2). First, we examined all variables with descriptive statistics, which include percentage and frequency for the categorical variable, mean, and standard deviation of continuous variables. Univariate analysis conducted; each risk factor is compared between male and female students. Then, we computed a summary score which gave 1-point for each risk factor that is present. This summary score is compared between male and female students using a Chi-square to measure the $p$-value. Furthermore, we used the odds ratio to identify the proportion of the study population at high risk according to gender, as well as frequency tables to determine the demographic characteristics of students in each year. SPSS application used to analyze our data.

\section{Ethical consideration}

Ethical approval was obtained from the Ethical Committee for Medical Research in Qassim University, Deanship of Research.

\section{Inclusion criteria}

All males and females medical students aged between 18 and 26 years.

\section{Exclusion criteria}

Non-medical students, Qassim University staff, students under the age of 18, or over 26 years were excluded from the study.

\section{Results}

\section{Demographic characteristics}

Table 1: Demographic characteristics

\begin{tabular}{ll}
\hline Variables & Frequency $(\%)$ \\
\hline Gender & $114(60.6)$ \\
Male & $74(39.4)$ \\
Female & \\
Age & $22 \pm 1.831$ \\
Mean \pm SD & \\
Year & $37(19.7)$ \\
$1^{\text {st }}$ & $41(21.8)$ \\
$2^{\text {nd }}$ & $38(20.2)$ \\
$3^{\text {rd }}$ & $39(20.7)$ \\
$4^{\text {th }}$ & $33(17.6)$ \\
$5^{\text {th }}$ & 188 \\
Total & \\
\hline
\end{tabular}

\section{Distribution of CVD risk factors by gender}

This Table 2 shows the measured risk factors of CVD for 188 medical students, 117 males and 
71 females. Eleven males students reported a positive history of smoking of $114(9.6 \%)$, while there is no history of smoking among 71 females students. About $17.3 \%$ of males were found obese, while obesity was lower among females (4.2\%). Both males and females reported that they do not have hypertension and diabetes. The random blood glucose for males and females was within normal limits, but the measured blood pressure showed a higher percentage of elevated blood pressure among males $(47.8 \%)$ in comparison to females (25.4\%). Perceived stress scale (PSS) exhibited that females were having a greater percentage of high stress $(34.3 \%)$, while in males, it was $14.4 \%$.

\section{Table 2: Distribution of risk by gender}

\begin{tabular}{llll}
\hline Risk factors & Males & Females & Chi-square (p-value) \\
\hline History of smoking & $(11) 9.6 \%$ & $0 \%$ & 0.007 \\
*Obesity & $(19) 17.3 \%$ & $(3) 4.2 \%$ & 0.008 \\
Self-reported hypertension & $0 \%$ & $0 \%$ & \\
Self-reported diabetes & $0 \%$ & $0 \%$ & \\
High stress scale & $(16) 14.4 \%$ & $(24) 34.3 \%$ & 0.002 \\
${ }^{* *}$ Elevated blood pressure & $(44) 47.8 \%$ & $(18) 25.4 \%$ & 0.003 \\
Elevated random blood glucose & $0 \%$ & $0 \%$ & \\
\hline${ }^{*}$ Including (obesity class 1, 2, and 3), * ${ }^{*}$ Including (elevated BP, hypertension 1 and 2).
\end{tabular}

According to the measured p-value in Table 2, there was a significant association between gender and the reported risk factors (smoking, obesity, stress, and blood pressure).

\section{Relationship between CVD risk factors and gender}

In Figures 1 and 2, the most higher risk factor in males was the elevated blood pressure, while in female's stress was the main risk.

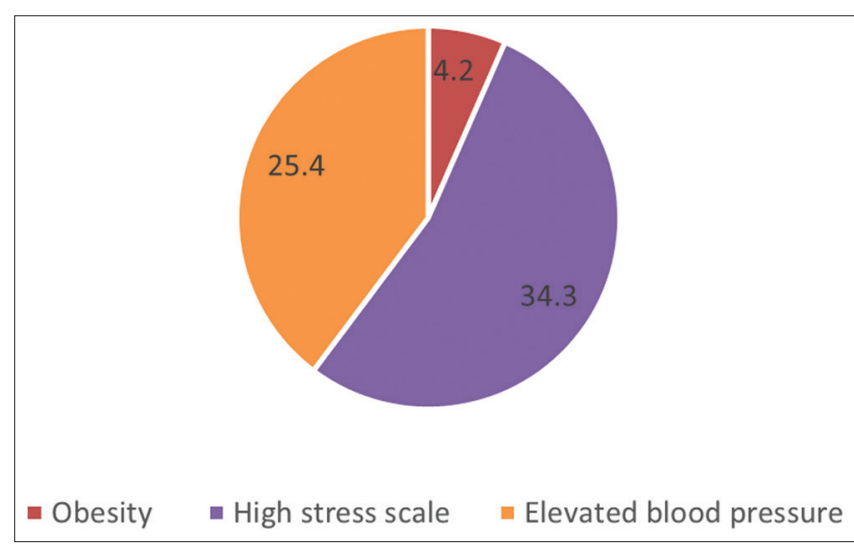

Figure 1: Relationship between risk and gender (females)

\section{The relationship between CVD risk factors and gender}

According to the calculated odds ratio (Table 3), females are 3.09 times more likely to have a high-stress scale in comparison to males. On the other hand, males are 4.7 more likely to be obese and they are also 2.7 more likely to have elevated blood pressure in comparison to females.

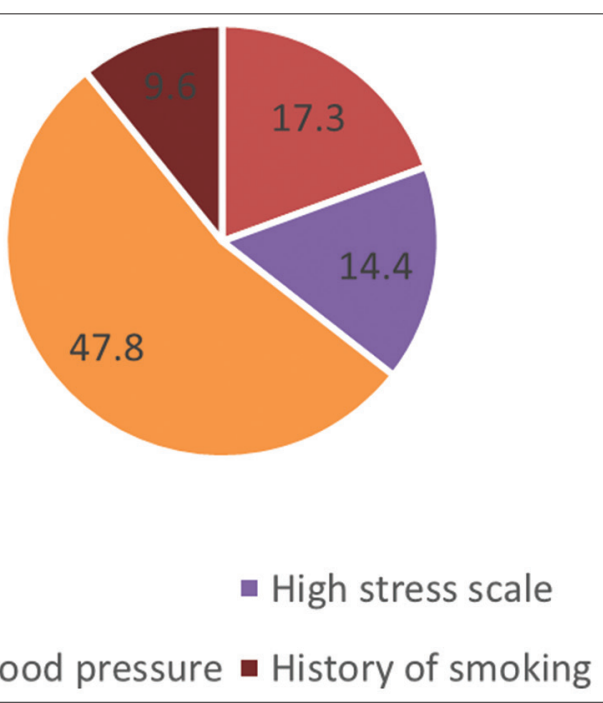

Figure 2: Relationship between risk and gender (males)

\section{Discussion}

This cross-sectional study showed the prevalence of CVD risk factors among males and females medical students in Qassim University, Al-Mulida, Qassim, Saudi Arabia in 2019/2020. Our result demonstrates that the most common risk factor in male's medical students was elevated blood pressure, while stress was the most common risk factor in females.

According to CVD risk factors, the result of this analysis showed the history of smoking in males was $9.6 \%$, while there was no history of smoking in females (Table 2). Overall, these findings were in accordance with the findings reported in a cross-sectional study, which showed that the prevalence of smoking in Saudi Arabia is $49.2 \%$ and $1.5 \%$ of them are females [11]. This may be due to social factors, stress, and academic loads which make some people to smoke cigarettes as a way to decrease stress. In some countries, they were equal. This is due to the general features of sex [12]. Now a day's female-to-male smoking ratio increase [13].

Our results also showed that elevated blood pressure was higher among males in comparison to females (Table 2). A previous study which was done among medical students in Qassim University reported that hypertension was higher in male participants compared to female participants [14]. A study revealed hypertension prevalence is higher among males, but females after the age of 60 have higher prevalence [7].

PSS exhibited that females were having a greater percentage of high stress, while in males; it was lower (Table 2). This is maybe due to the load of work, the burden of exams, fear of poor academic performance and future competence, and sedentary lifestyle. Another study stated that chronic was related to worse prognosis in patients with known CVD [7]. 
Table 3: Relationship between CVD risk factors and gender

\begin{tabular}{lllll}
\hline CVD risk factors & Males & Females & Odds ratio & 95\% confidence interval \\
\hline High stress & $16(14.4 \%)$ & $24(34.3 \%)$ & 3.098 & $1.502-6.389$ \\
Obesity & $19(17.3 \%)$ & $3(4.2 \%)$ & 4.7 & $1.346-16.643$ \\
Elevated BP & $44(47.8 \%)$ & $18(25.4 \%)$ & 2.7 & $1.377-5.292$ \\
\hline
\end{tabular}

Our results also revealed a higher prevalence of obesity in males compared to females (Table 2). This is probably due to lack of exercise as a result of busy schedules, eating junk food, and poor diet. There was a study that determined the prevalence of obesity in KSA among females and males between the ages of 30 and 70 years. The study found that overweight prevalence is more in males while in females it was lower [15]

\section{Limitations}

There are some limitations in our study:

1. We could not measure the lipid profile as the participants must be fasting for at least $8 \mathrm{~h}$.

2. There was the inadequate response from male medical students to participate in our research.

3. It was hard to find a male collector

\section{Conclusion}

Based on our results (Table 2), many risk factors were greater among males, including (elevated blood pressure $47.8 \%$, obesity $17.3 \%$, and smoking $9.6 \%)$. On the other hand, these risk factors were lower in females, but they have a higher stress scale $34.3 \%$ in comparison to males. According to the measured $\mathrm{p}$-value, there was a strong association between the reported risk factors and gender.

\section{Recommendations}

A balanced diet, decrease salt intake, and regular exercise at least 3 days weekly to maintain a healthy weight. Try to quit smoking by avoiding triggers. Get enough hours of sleep, take a deep breath, walk for 30 min daily, and try relaxation techniques as yoga to reduce stress.

We recommend to do further researches to determine the causes of high stress among females and to assess CVD risk factors among the general population in Saudi Arabia.

\section{References}

1. Laslett LJ, Alagona P, Clark BA, Drozda JP, Saldivar F, Wilson SR, et al. The worldwide environment of cardiovascular disease: Prevalence, diagnosis, therapy, and policy issues. J Am Coll Cardiol. 2012;60 Suppl 25:S1-49. https://doi.org/10.1016/j. jacc.2012.11.002

PMid:23257320

2. World Health Organization. Available from: https://www.who int/news-room/fact-sheets/detail/noncommunicable-diseases. [Last accessed on 2020 January 20].

3. Motlagh B, O'Donnell M, Yusuf S. Prevalence of cardiovascular risk factors in the Middle East: A systematic review. Eur $J$ Cardiovasc Prev Rehabil. 2009;16(3):268-80. https://doi. org/10.1097/hjr.0b013e328322ca1b

PMid:19398913

4. Mahmoud AE. Prevalence of cardiovascular disease risk factors among Egyptian and Saudi medical students: A comparative study. J Egypt Public Health Assoc. 2015;90(1):35-9. https://doi. org/10.1097/01.epx.0000460969.93981.c2

PMid:25853544

5. Appelman $Y$, van Rijn BB, Ten Haaf ME, Boersma E, Peters SA Sex differences in cardiovascular risk factors and disease prevention. Atherosclerosis. 2015;241(1):211-8. https://doi. org/10.1016/j.atherosclerosis.2015.01.027

PMid:25670232

6. Alqurashi KA, Aljabri KS, Bokhari SA. Prevalence of diabetes mellitus in a Saudi community. Ann Saudi Med. 2011;31(1):1923. https://doi.org/10.4103/0256-4947.75773 PMid:21245594

7. Sandberg K, Ji H. Sex differences in primary hypertension. Bio Sex Differ. 2012;3(1):7. https://doi.org/10.1186/2042-6410-3-7 PMid:22417477

8. Greenland P, LaBree L, Azen SP, Doherty TM, Detrano RC Coronary artery calcium score combined with Framingham score for risk prediction in asymptomatic individuals. JAMA. 2004;291(2):210-5. https://doi.org/10.1001/jama.291.2.210 PMid: 14722147

9. Cohen S. Scale Stress. Perceived Stress Scale-mind Garden; 1994. Available from: http://www.mindgarden. com>documents>Pe. [Last accessed on 2020 January 20].

10. Nohair SA, Mohaimeed AA, Sharaf F, Naeem Z, Midhet F, Homaidan HA, et al. Risk profile of coronary heart disease among the staff members of Qassim university, Saudi Arabia. Int J Health Sci. 2017;11(1):30-4.

PMid:28293152

11. Abdelwahab SI, El-Setohy $M$, Alsharqi $A$, Elsanosy $R$, Mohammed UY. Patterns of use, cessation behavior and sociodemographic factors associated with smoking in Saudi Arabia: A cross-sectional multi-step study. Asian Pac J Cancer Prev. 2016;17(2):655-60. https://doi.org/10.7314/apjcp.2016.17.2.655 PMid:26925659

12. Waldron I, Bratelli G, Carriker L, Sung WC, Vogeli C, Waldman E. Gender differences intobacco use in Africa, Asia, the Pacific, and Latin America. Soc Sci Med. 1988;27(11):1269-75. https:// doi.org/10.1016/0277-9536(88)90357-7 PMid:3206258

13. Bilal $U$, Beltrán $P$, Fernández $E$, Navas-Acien $A$, Bolumar $F$, Franco M. Gender equality and smoking: A theory-driven approach to smoking gender differences in Spain. Tob Control. 2016;25(3):295-300. https://doi.org/10.1136/ tobaccocontrol-2014-051892

PMid:25701858 
14. AlWabel A, Almufadhi M, Alayed F, Aloraini A, Alobaysi $\mathrm{H}$, Alalwi R. Assessment of hypertension and its associated risk factors among medical students in Qassim university. Saudi J Kidney Dis Transpl. 2018;29(5):1100-8. https://doi. org/10.4103/1319-2442.243959
PMid:30381506

15. Al-Nozha MM, Al-Mazrou YY, Al-Maatouq MA, Arafah MR Khalil MZ, Khan NB, et al. Obesity in Saudi Arabia. Saudi Med J. 2005;26(5):824-9. https://doi.org/10.1016/j.jsha.2009.06.007 PMid:15951877 


\section{Appendices}

\section{Appendix 1: Questionnaire}

\begin{tabular}{ll}
\hline Personal data & $\ldots \ldots \ldots \ldots \ldots \ldots \ldots \ldots \ldots \ldots \ldots \ldots$ \\
Name (optional): & $\ldots \ldots \ldots \ldots \ldots \ldots \ldots \ldots \ldots \ldots \ldots \ldots \ldots \ldots$ \\
\hline Age: & $\square$ Female $\square$ Male \\
Gender: & $\ldots \ldots \ldots \ldots \ldots \ldots$ \\
Weight $(\mathrm{kg}):$ & $\ldots \ldots \ldots \ldots \ldots$ \\
Height $(\mathrm{cm}):$ & $\ldots \ldots \ldots$ \\
\hline
\end{tabular}

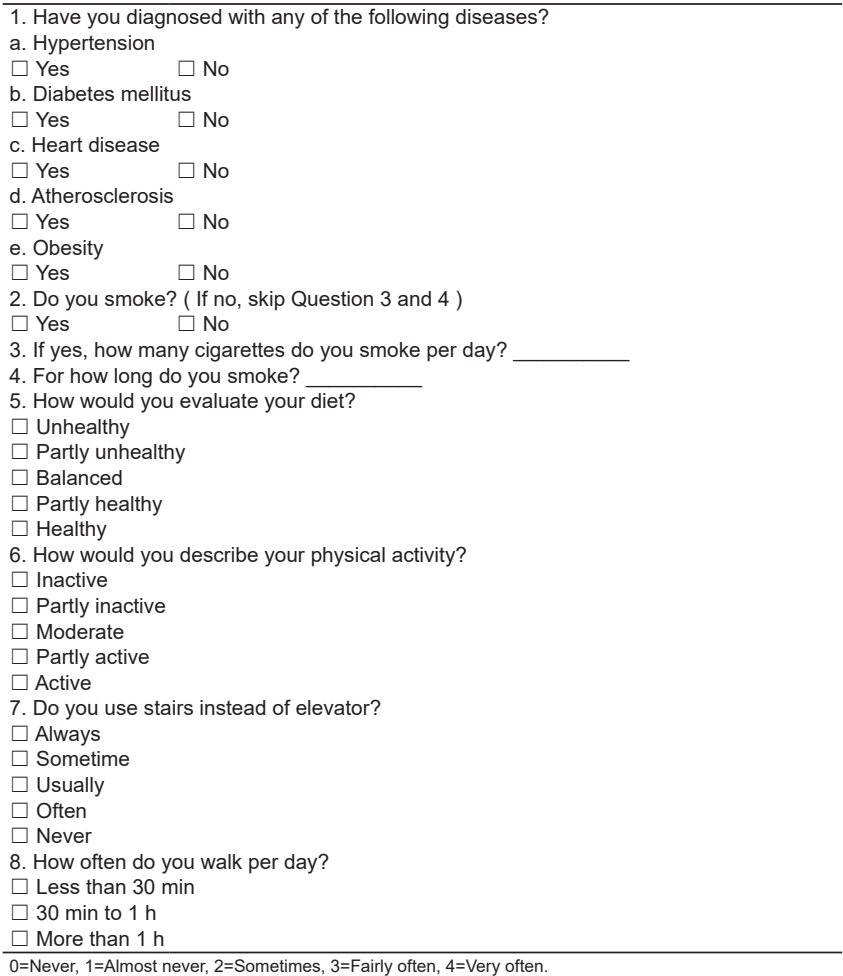

Body mass index (BM)
Blood pressure (BP)

Random blood glucose (RBG)

Waist circumference

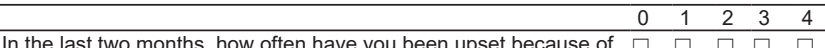

something that happened unexpectedly?
In the last month, how often have you felt that you were unable to $\quad \square \quad \square \quad \square \square \square$

control the important things in your life?

In the last month, how often have you felt nervous and "stressed"? $\quad \square \quad \square \quad \square \quad \square$

In the last month, how often have you felt confident about your $\quad \square \quad \square \quad \square \quad \square \quad \square$

ability to handle your personal problems?

In the last month, how often have you felt that things were going $\quad \square \quad \square \quad \square \quad \square$

your way?

In the last month, how often have you found that you could not

cope with all the things that you had to do?

In the last month, how often have you b

irritations in your life?

In the last month, how often have you felt that you were on top of $\quad \square \quad \square \quad \square \quad \square \quad \square$

things?

In the last month, how often have you been angered because of

things that were outside of your control?

In the last month, how often have you felt difficulties were piling up $\quad \square \quad \square \quad \square \quad \square$

so high that you could not overcome them? 


\section{Appendix 2: Consent Form}

The purpose of the study

You are invited to take part in a cross-sectional study that evaluates the risk factors of cardiovascular disease among male and female medical students at Qassim University.

If you agree to take part in this study, please read the information carefully and complete the attached questionnaire which will take, on average, 5-10 min to be completed and another 5-10 min for taking measurements of blood pressure, waist circumference, BMI, and blood glucose using a finger prick blood sample and a glucometer, which may be slightly painful.

All these measurements will be performed by a nurse.

Confidentiality

The information you provide is completely confidential and only researchers are able to reach them.

Although you provide as with your information, it will be private and will not be publicized; instead, you will get an ID number and the analysis will be based on that figure. Furthermore, the result will be published as a group and not individually.

If you have any inquires/complains, please contact with Dr. Sultan ALNohair

Drsultan1@qumed.edu.sa

I have read the above information, or been read to me,

I understand that there are no risks on me if I participate in this trial,

I have had the opportunity to ask questions about the research topic and was replied to all my questions clearly and I agree voluntarily to participate as a participant in this research. 